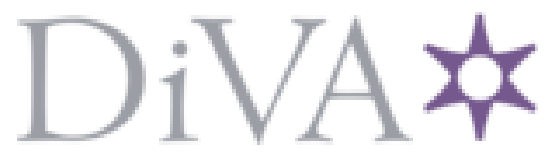

http://www.diva-portal.org

\title{
Postprint
}

This is the accepted version of a paper published in Scandinavian Journal of Public Health. This paper has been peer-reviewed but does not include the final publisher proof-corrections or journal pagination.

Citation for the original published paper (version of record):

Borisova, L., Martinussen, P E., Rydland, H T., Stornes, P., Eikemo, T A. (2017)

Public evaluation of health services across 21 European countries: The role of culture.

Scandinavian Journal of Public Health

https://doi.org/10.1177/1403494816685920

Access to the published version may require subscription.

N.B. When citing this work, cite the original published paper.

Permanent link to this version:

http://urn.kb.se/resolve?urn=urn:nbn:se:uu:diva-315249 


\section{Public evaluation of health services across 21 European countries: The role of culture}

Liubov V. Borisova ${ }^{1}$, Pål E. Martinussen ${ }^{2}$, Håvard T. Rydland ${ }^{2}$, Per Stornes ${ }^{2}$, Terje A. Eikemo $^{2}$

${ }^{1}$ Department of Sociology, Uppsala University, Sweden

${ }^{2}$ Department of Sociology and Political Science, Norwegian University of Science and Technology (NTNU), Trondheim, Norway

Corresponding author: Liubov V. Borsiova, Department of Sociology, Uppsala University, Box 624, 75126 Uppsala, Sweden. Tel: + 46184717682. Email: liubov.borisova@soc.uu.se

Accepted by the Scandinavian Journal of Public Health, 2017. 


\section{Abstract}

Aim. This paper examines role of cultural values in understanding people's satisfaction with health services across Europe.

Methods. We used multilevel linear regression analysis on the $7^{\text {th }}$ round of the European Social Survey (ESS) from 2014, including approximately 40,000 respondents from 21 countries. Preliminary intraclass correlation analyses lead us to believe that some explanations of variance in the dependent variable were to be found at the country level. In search of country-level explanations, we attempted to account for the role of national culture in influencing citizens' attitudes towards health systems. This was done by using Hofstede's dimensions of power distance (PDI), individualism (IDV), masculinity (MAS), and uncertainty avoidance (UAI), giving each country in the survey a mean aggregated score.

Results. In our first model with individual level variables, being female, having low or medium education, experiencing financial strain, and reporting bad health and unmet medical needs were negatively associated with individual satisfaction with national healthcare systems, with the latter variable showing the strongest effect. After including Hofstede's cultural dimensions in our multilevel model, we found that the power distance index variable had a negative effect on the dependent variable, significant at a 0.1 level.

Conclusions. It is possible that in national cultures associated with autocracy and hierarchy, citizens are likely to evaluate their national health system more negatively.

Keywords: Public evaluation of healthcare; satisfaction with healthcare; Hofstede's cultural dimensions; welfare typology; multilevel analysis; Europe; European Social Survey 


\section{Background}

There is an increasing interest in measuring satisfaction with health services and health system performance [1-3]. Evaluation of health services by consumers is important since it might influence health outcomes, as it is the 'voice' of patients in expressing their preferences [4] and therefore essential to patient-orientation-driven healthcare. Furthermore, healthcare satisfaction is one of the alternative ways to measure healthcare quality and performance, and the results are typically used to identify whether a system is performing well enough and to identify areas where it can improve [2].

Differences in satisfaction with healthcare are most often attributed to individual consumer characteristics [5-9], healthcare system types [10-13] and healthcare delivery features and spheres [7,10,14-21]. However, potential differences between countries, cultures and values are rarely taken into consideration. This study aims to fill some of these gaps by examining the role of cultural values in understanding people's satisfaction with health services across Europe.

The field of 'satisfaction with healthcare' has been rapidly developing since the 1960s [22]. Patient satisfaction with the service they receive has become part of healthcare quality assurance [23] and the evaluation of general healthcare services outcomes [24]. Studies on healthcare satisfaction can very broadly be classified into two separate categories: the first is patient satisfaction with (particular) healthcare services $[6,7,9,17,25-29]$, and the other is often referred to as public satisfaction with or support for the healthcare system in general [30-34]. Studies in these two areas differ significantly in terms of conceptualisation, methodology, goals and aims. On the one hand, patient satisfaction is analysed most often on the basis of patient surveys administered after treatment or hospital stay. Hence, most of the subjects involved usually have some kind of health problem, which is being resolved. On the other hand, studies relating to public satisfaction with health services are primarily based on population surveys. In this case, very often the respondents have not had contact with healthcare institutions directly prior to the questionnaire, or even if they did, their conditions and reasons for seeking care are most probably very diverse. Thus, the latter kind of survey does not measure satisfaction with healthcare per se. Rather, it looks at what can be referred to as 'public support', 'public opinion' or 'population evaluation' of healthcare, and it is the main theme of the present paper.

There is a plethora of studies analysing the public support of welfare regimes, social policies and redistribution practices. Most of these studies document little change in the attitudes of the population towards the welfare states [35-38]. We also know that 
universal healthcare is strongly supported by the public [39]. Characteristics such as institutional features (for example, number of GPs), overall performance of the healthcare system and, to some extent, respondents' individual characteristics (for example, health status, age, gender, ethnic groups) [4,40] also influence the public opinion of health services. However, research has not been able to link welfare regimes and healthcare classifications to the variation in these attitudes. With the expansion of the European Union and rapid political and economic transition of the former communist states, Europe is increasingly diverse. No longer can we rely, for instance, on the famous 'three worlds' typology of Esping-Andersen [41] in our understanding of regimes and country differences. Beyond that, textbook separation of healthcare systems into tax-based and social health insurance (SHI) ideal types becomes even less useful when we consider the healthcare systems of the Central and Eastern European (CEE) countries. The CEE health systems are often referred to as primarily 'hybrid' SHI systems, as they truly incorporate the features of both SHI and tax-based models [42].

There is also a causality dilemma of what comes first: people's attitudes or the institutional programs within each welfare state [43]. While it may be true that program structure influences attitudes toward welfare states, an equally plausible argument is that collective values are a motivating force in determining the institutional structure of welfare state [44]. For instance, social democratic welfare states typically build on an ideology emphasizing collectivism, de-commodification and minimal market dependency, while liberal welfare states, on the other hand, are characterized by an obsession with market efficiency and commodification, and the minimalist social policy of laissez faire is in keeping with their ideals [43].

Therefore, because most research on healthcare system evaluations fails to come to a conclusion about what influences those evaluations and to create a precise 'recipe' for policy-makers and other researchers, there is a need to investigate the cross-country and perhaps the cross-cultural differences in more detail. Moreover, the exact institutional setup and country characteristics of welfare and healthcare systems (such as the type of healthcare, culture of out-of-pocket payments) are inevitably influenced by a society's general cultural attitudes, which have been developed over centuries. Therefore, this paper sets out to explore the effect of cultural climate in a range of European countries on the public evaluation of healthcare services relying on Geert Hofstede's commonly used cultural dimensions [45,46] of power distance (PDI), individualism (IDV), masculinity (MAS), and uncertainty avoidance (UAI). The main research questions posed here are: 
- Does the public evaluation of healthcare services differ across European countries and Israel, and if so, are cross-country differences significant?

- Can the different cultural orientations explain some variation in public evaluation of health services across Europe and Israel?

\section{Data and methods}

The study is based on the $2014\left(7^{\text {th }}\right)$ round of the European Social Survey (ESS). Our study included a total of 39,894 respondents from 21 countries of the European Union (EU), the European Economic Area (EEA) and Israel [1]. The ESS is funded by the European Commission, the European Science Foundation and academic bodies, and covers a broad range of social topics. The latest survey also contains a rotating module on the social determinants of health [47]. Data collection was based on face-to-face interviews with individuals aged 15 and above living in private households. Response rates ranged from $31 \%$ in Germany to $68 \%$ in the Czech Republic, and are overall similar to previous rounds of the ESS [48]. In this paper the individual-level ESS dataset is accompanied by the country-level datasets from the World Bank (WB), the World Health Organization (WHO), and Hofstede's cultural dimensions. All data manipulation and analysis was performed in Stata SE 14 [49].

\section{Dependent variable}

The dependent variable, the evaluation of healthcare as a whole, was derived from the following item: 'Please say what you think overall about the state of health services in [country] nowadays?' The responses are distributed on a scale from 0 ('extremely bad') to 10 ('extremely good'). The variable was treated as numeric.

\section{Country-level explanatory variables}

\section{Cultural climate}

The main country-level explanatory variable is the cultural climate. Geert Hofstede has published seminal research on culture, measured across countries through "cultural dimensions' [45,46]. Hofstede defines culture as 'the collective programming of the mind that distinguishes the members of one group or category of people from another' [46: 9]. To Hofstede, value systems are the core elements of culture, while the dimensions of culture make it possible to identify differences between cultures in a systematic, yet not overly simplified way.

Hofstede originally came up with the four main dimensions [2] of culture: 
- 'Power distance (index)' (PDI) represents the perception of inequality of power distribution between the most and the least powerful; it also reflects how ready the least well-off are to fight against (or accept) inequality in the society [46]. This reflects how autocratic/hierarchic or democratic the society is: the higher the index, the more autocratic is the culture and people's perceptions.

- 'Individualism' (IDV) vs. collectivism is a common typology in cross-cultural psychology[50] that reflects how much individuals identify themselves with others and groups (not the state). The higher the index, the more individualistic the culture is.

- 'Masculinity' (MAS) vs. femininity reflects the emotional gender roles in a society; but while 'masculine' refers to imposing a more assertive, competitive culture, it does not necessarily refer to 'male'. At the same time, in feminine cultures' relationships, caring behaviour and quality of life are valued [46]. In more masculine societies, the gap between men and women is rather big, hence the higher the score, the more materialistic and competitive the culture is, and the larger the gap is between male and female roles in the society.

- 'Uncertainty avoidance (index)' (UAI) reflects a society's ability to accept, or its desire to avoid uncertainty - namely ambiguous, unstructured situations; it also reflects tolerance of new ideas and change [46]. Hence, the higher the score, the more emotional the culture might be, and the less pragmatic and less tolerant people tend to be.

The cultural dimensions scores for European countries are presented in Table 1. Hofstede's dimensions are often used to create a compound summary index, which is relevant for comparative research but difficult to interpret when used in econometric analysis. Moreover, summarising the indices might dilute the peculiarities of culture (some countries score high on one dimension, but not on others). We therefore chose to include Hofstede's four dimensions as separate variables in our analysis rather than using typologies of countries, since our goal is to uncover how each of the dimensions affects support for the healthcare system rather than to engage in the cultural typology debate.

(Table 1)

\section{Other macro-level indicators}

Other country-level explanatory variables and controls had to be taken into account as well. We follow the research of Wendt et al. [40] to identify country-level factors that might influence the evaluation of healthcare. The authors argue that total health 
expenditures, out-of-pocket payments, and the number of physicians are just some of the healthcare institutional characteristics that explain some part of evaluation rates of healthcare services. The authors find that the institutional arrangements are indeed important, as they involve 'individual experiences' [40: 188]. Hence, we also include models with the national total health expenditure (THE) as a percentage of the gross domestic product (GDP), out-of-pocket payments as a percentage of THE, and the number of physicians per 1000 people [51-53]. Since the survey data was collected in 2014, we used the 2013 or the most recent available macro figures. Table 1 displays descriptive statistics for all country level variables, along with the country average score on the dependent variable. We observe that Hungary (3.35) has the lowest average healthcare satisfaction, while Belgium (7.48) has the highest.

\section{Individual-level explanatory variables}

All of the micro-level indicators have been taken from the ESS dataset. We start with the standard demographics (descriptive statistics for the variables are presented in table 2):

- Gender: a binary variable coded 1 for women and 0 for men.

- Age: a numerical variable coded into age groups separated by 10 years (from 24 and under, 25-34, and so on, up to 75 and above, with the latter being a reference category for analysis).

- Education: measured initially as the highest level of education in accordance with the International Standard Classification of Education (ISCED); further coded into three dummy educational groups: low (lower secondary education or less), medium (upper secondary or advanced vocational education), and high (tertiary education), with the latter being a reference category in the analysis.

- Financial strain: a binary variable with respondents finding it 'difficult' or 'very difficult' to manage on current income coded as 1 , and those coping or living comfortably coded as 0 .

- Health (self-reported): a binary variable with respondents assessing their health to be 'bad' or 'very bad' coded as 1, and those reporting 'very good', 'good', and 'fair' health given the value 0 .

- Unmet needs: a binary variable with respondents reporting having been unable to get a medical consultation or treatment for the last 12 months coded as 1 , with the remaining group as a reference.

(Table 2) 


\section{Multilevel analysis}

Multilevel analysis (MLA) was performed on the ESS data in three steps. First, the model without any explanatory variables - a so-called empty model - was run in order to calculate intraclass correlation and analyse the amount of variation present at the macro level. Second, level 1 control variables were added to the model to account for individual explanations and variations in healthcare satisfaction. Finally, country level variables were added in multiple steps: culture, healthcare financing, and healthcare availability. To facilitate the interpretation of coefficients, individual level variables were not assigned random effects; hence their association with the dependent variable is similar in different countries. Due to limitations of the sample (a relatively low number of countries), culture and other macro level indicators could not be analysed within the same model, and different sets of models were run and then compared. Bayesian information criterion (BIC) [54], likelihood ratio test and Snijders and Bosker [55] Rsquared were used for comparing the models.

\section{Results}

The empirical results are presented in Table 3. After running the first empty model, we found that the intraclass correlation (ICC) for public evaluation of healthcare is 0.213 , which means that $21.3 \%$ of the variation is attributed to the country level. This is quite a high ICC for cross-country research, and particular for a study on the perceptions of individuals (as opposed to objective data). Hence, MLA is clearly needed to account for the structure of the data.

(Table 3)

In our first model only individual level variables were included, and the results offer few surprises. The evaluation of healthcare by age group shows a slight curvilinear effect; all age groups are more negative about the healthcare system than the youngest and eldest groups, with the middle range 55-64 age group showing the strongest negative assessment. Men tend to evaluate healthcare services more positively than do women, but this is also true for other perception rates. The education variables included in the model show a significant negative impact, meaning that the low and medium educated tend to be more critical of healthcare systems than individuals with high (tertiary) education. The variable capturing financial strain has a significant negative impact: thus, respondents who experience difficulties with their present financial situation evaluate healthcare more negatively than those who are in a better financial situation. The individual level model also includes subjective health as an explanatory variable, which is significant and negative; hence, those who report better health also 
evaluate healthcare more positively. Lastly, unmet need has a significant negative impact on healthcare satisfaction, implying that respondents who experienced that their medical needs were not met by the healthcare system during the last year assessed the system more negatively than those without that experience.

The individual level variables included in the models explain $8.4-12.1 \%$ of the total individual level variance, and we do not see substantial changes in the coefficients when expanding the individual level model with macro variables.

After including Hofstede's cultural dimensions in our multilevel model, we found that the power distance index variable had a negative effect on the dependent variable, significant at a 0.1 level. This means that in national cultures associated with autocracy and hierarchy, citizens are likely have a lower opinion of their national health system. Individuality and masculinity, with p-values of 0.109 and 0.105 , are also worth mentioning. With the low number of level 2 observations (i.e., the number of countries included in the analysis), only very strong effects can be expected to have the highest levels of statistical significance, and country level effects with lower levels of significance also deserve our attention. Following from this, our results indicate that national cultures characterized by individualism are likely to assess their national health system more positively, while materialistic and competitive cultures with traditional gender role gaps are likely to assess healthcare negatively. The cultural dimension of uncertainty avoidance did not show significant results $(\mathrm{p}=0.2)$.

The other country level variables showed significant associations with healthcare satisfaction when added one-by-one. As expected, high physician density and a higher share of GDP spent on healthcare is positively associated with healthcare evaluation. A high degree of out-of-pocket payment is negatively associated, but with a coefficient of -0.053 and a p-value of 0.101 , this association is somewhat weaker than for the other country level variables. When all institutional variables are included in one model, only physician density turns out to be significant, while both total health expenditures and out-of-pocket payments do not affect healthcare evaluations any longer.

When examining the fit and explanation power of the different models, we found the THE model to be the strongest one (lowest BIC and significant likelihood ratio test). Including the rate of total healthcare expenditure explained $41.2 \%$ of country-level variance, compared to $33.8 \%$ explained by the cultural dimensions. The overall fit of the last model (institutional, including physician density, THE and OOP) was worse than the THE model, even though it explained more second-level variation (47.5\%). When we performed likelihood ratio tests in STATA and compared the macro level 
expansions to both the 'empty' baseline model and the individual level model, the THE model proved to be the expansion with the highest level of statistical significance.

To sum up, we can note that while individual-level variables do explain some variation in healthcare evaluations, some country-level variables are also significant and create a reasonable model fit for the data at hand. In general, the 'hard' macro variables measuring healthcare availability and financing show somewhat stronger associations with positive healthcare evaluations than the 'soft' cultural dimensions.

\section{Discussions and conclusions}

This article set out to analyse satisfaction with healthcare by applying a cross-cultural paradigm instead of looking into the details of institutional setup, while controlling for the main individual-level characteristics of the respondents. We found that the individual-level characteristics, such as gender, age, education and financial strain, as well as subjective health and unmet need of healthcare, do predict the evaluations of healthcare as expected. These results are in line with those of previous studies on public evaluation of healthcare $[4,40]$.

When it comes to the country level effects, several findings need to be discussed. First, consistent with other studies, we do find that healthcare characteristics at the country level have an impact on healthcare evaluation $[4,39,40]$. In our analysis, physicians density, total health expenditures and out-of-pocket payments all turned out to be significant predictors of healthcare evaluations. These findings are expected, as easier access to physicians (due to increased physician density) would indeed make people more satisfied with the quality of healthcare services overall. Smaller out-of-pocket payments would also generally increase positive evaluation of health services. Overall spending on healthcare provision is also an important factor in establishing a positive regard for health services and, at the end of the day, health services quality assurance [24]. Still, consistent with other studies [17,21], physicians density seem to be of primary importance for establishing a positive regard towards healthcare, when the other factors are also controlled for.

Second, the effects of culture on healthcare evaluations need to be addressed. The results of this study indicate that cultural dimensions do indeed explain some of the variation in the public support for healthcare. We found that the strongest cultural dimension relevant for healthcare evaluations is the power distance index (PDI), which refers to the hierarchy and distribution of power. In societies with lower PDI, people perceive the distribution of power to be more equal between those on the 'top' and the 'bottom' of the power hierarchy. We found, therefore, that people from countries with 
stronger anti-hierarchical and egalitarian cultures tend to evaluate healthcare services more positively. This relationship may partly be explained by the fact that people from these countries tend to view institutions as equal and not domineering, even though the institutions do possess power. Hence, the evaluations of said institutions are more positive.

Other cultural dimensions might not be particularly important for explaining support for healthcare services. While the effects are weak, they could still point in the direction that in more caring and gender-egalitarian societies, people tend to evaluate health services more positively.

Overall, this paper contributes to the literature on satisfaction with healthcare in several ways. First, it introduces culture into the discourse on healthcare evaluations, so that we can account for it when analysing the public evaluation of healthcare. Second, we include a wide range of countries across all of Europe, including the new EU member states, and Israel. Third, the methods used in this paper (MLA) are rarely used in the literature on satisfaction with healthcare.

There are some limitations to this study as well. First, exploring the potential effects of culture on healthcare is limited to the instruments measuring culture. Culture is a broad, multidimensional and qualitative concept. Therefore, using Hofstede indices as an attempt to 'quantify' culture also faces a lot of criticism [56]. Nevertheless, while the options are limited, certain links and relations identified through quantitative studies could point in the direction of further - perhaps qualitative - analysis of culture and healthcare evaluations. Second, methodologically we were limited to only 21 units (countries) at the second level of our analysis. This is a relatively low number; hence, we could not test cultural dimensions and other institutional characteristics within the same models. This could be an idea for future research.

\section{Funding statement}

No additional funding was granted to carry out this study.

\section{Declaration of conflicting interests}

Authors declare that there is no conflict of interest related to this study.

\section{Notes}

(1) Israel was included to provide bigger cultural diversity, as well as for methodological reasons. List of countries included: Austria (AT), Belgium (BE), Czech 
Republic (CZ), Denmark (DK), Estonia (EE), Finland (FI), France (FR), Germany (DE), Great Britain (GB), Hungary (HU), Ireland (IE), Israel (IL), Lithuania (LT), Netherlands (NL), Norway (NO), Poland (PL), Portugal (PT), Slovenia (SI), Spain (ES), Sweden (SE), Switzerland (CH).

(2) In recent years, a fifth and sixth dimension have also been developed: 'long-term orientation' and 'indulgence'. However, these are not addressed here because of substantial and methodological considerations: first, neither of the new dimensions is considered to be of much relevance to our research question; and second, since it is not possible to include all six dimensions as level 2 variables in the same model we elected to use the original four dimensions.

\section{References}

1. Bleich SN, Özaltin E, Murray CJL. How does satisfaction with the health-care system relate to patient experience? Bull World Health Organ. 2009;87:271-8.

2. Busse R, Valentine N, Lessof S, Prasad A, van Ginneken E. Being responsive to citizens' expectations: the role of health services in responsiveness and satisfaction. In: McKee M, Figueras J, editors. Health systems, health, wealth and societal well-being: assessing the case for investing in health systems. Maidenhead, Berkshire: Open University Press; 2012.

3. Papanicolas I, Cylus J, Smith PC. An analysis of survey data from eleven countries finds that "satisfaction" with health system performance means many things. Health Aff Proj Hope. 2013;32(4):734-42.

4. Crow R, Gage H, Hampson S, Hart J, Kimber A, Storey L, et al. The measurement of satisfaction with healthcare: implications for practice from a systematic review of the literature. Health Technol Assess. 2002;6(32):1-244.

5. Asadi-Lari M, Tamburini M, Gray D. Patients' needs, satisfaction, and health related quality of life: towards a comprehensive model. Health Qual Life Outcomes. 2004;2(32).

6. Hall JA, Dornan MC. Patient sociodemographic characteristics as predictors of satisfaction with medical care: A meta-analysis. Soc Sci Med. 1990;30(7):811-8.

7. Kalda R, Põlluste K, Lember M. Patient satisfaction with care is associated with personal choice of physician. Health Policy. 2003;64(1):55-62. 
8. Xiao H, Barber JP. The Effect of Perceived Health Status on Patient Satisfaction. Value Health. 2008;11(4):719-25.

9. Young GJ, Meterko M, Desai KR. Patient Satisfaction with Hospital Care: Effects of Demographic and Institutional Characteristics. Med Care. 2000;38(3):325-34.

10. Grol R, Wensing M, Mainz J, Jung HP, Ferreira P, Hearnshaw H, et al. Patients in Europe evaluate general practice care: an international comparison. Eur Task Force Patient Eval Gen Pract Care Eur Br J Gen Pract J R Coll Gen Pract. 2000;50(460):882-7.

11. Grubaugh SG, Santerre RE. Comparing the Performance of Health Care Systems: An Alternative Approach. South Econ J. 1994;60(4):1030-42.

12. Mossialos E. Citizens' Views on Health Care Systems in the 15 Member States of the European Union. Health Econ. 1997;6(2):109-16.

13. Wensing M, Baker R, Szecsenyi J, Grol R. Impact of national health care systems on patient evaluations of general practice in Europe. Health Policy. 2004;68(3):353.

14. Bautista RED, Glen ET, Shetty NK. Factors associated with satisfaction with care among patients with epilepsy. Epilepsy Behav. 2007;11(4):518-24.

15. Bikker AP, Thompson AGH. Predicting and comparing patient satisfaction in four different modes of health care across a nation. Soc Sci Med. 2006;63(6):1671-83.

16. Jensen HI, Ammentorp J, Kofoed P-E. User satisfaction is influenced by the interval between a health care service and the assessment of the service. Soc Sci Med. 2010;70(12):1882-7.

17. Kroneman MW, Maarse $\mathrm{H}$, Zee $\mathrm{J}$ van der. Direct access in primary care and patient satisfaction: A European study. Health Policy. 2006;76(1):72-9.

18. Nguyen Thi PL, Briançon S, Empereur F, Guillemin F. Factors determining inpatient satisfaction with care. Soc Sci Med. 2002;54(4):493-504.

19. Nickel S, Thiedemann B, von dem Knesebeck O. The effects of integrated inpatient health care on patient satisfaction and health-related quality of life: 
Results of a survey among heart disease patients in Germany. Health Policy. 2010;98(2-3):156-63.

20. Sixma HJ, Spreeuwenberg PMM, van der Pasch MAA. Satisfaction with the general practitioner - A two-level analysis. Med Care. 1998 Feb;36(2):212-29.

21. Wensing M, Vedsted P, Kersnik J, Peersman W, Klinenberg A, Hearnshaw H, et al. Patient satisfaction with availability of general practice: an international comparison. Int J Qual Health Care. 2002;14(2):111.

22. Ware JE, Davies AR, Stewart AL, Rand Corporation. The measurement and meaning of patient satisfaction: a review of the literature. Santa Monica, Calif.: Rand Corporation; 1977.

23. Cleary PD, McNeil BJ. Patient satisfaction as an indicator of quality care. Inq $\mathbf{J}$ Med Care Organ Provis Financ. 1988;25(1):25-36.

24. Hsiao W, Heller PS. What should macroeconomists know about health care policy? Washington, DC: IMF; 2007. (IMF working paper, 07/13).

25. Abramowitz S, Coté AA, Berry E. Analyzing patient satisfaction: a multianalytic approach. Qual Rev Bull. 1987;13(4):122-30.

26. Gill L, White L. A critical review of patient satisfaction. Leadersh Health Serv. 2009;22(1):8-19.

27. Kerssens JJ, Groenewegen PP, Sixma HJ, Boerma WGW, van der Eijk I. Comparison of patient evaluations of health care quality in relation to $\mathrm{WHO}$ measures of achievement in 12 European countries. Bull World Health Organ. 2004;82(2):106-14.

28. Kurata JH, Watanabe Y, McBride C, Kawai K, Andersen R. A comparative study of patient satisfaction with health care in Japan and the United States. Soc Sci Med. 1994;39(8):1069-76.

29. Lin BY-J, Lin C-C, Lin YK. Patient satisfaction evaluations in different clinic care models: Care stratification under a national demonstration project. Health Place. 2010;16(1):85-92. 
30. Adang E, Borm G. Is there an association between economic performance and public satisfaction in health care? Eur J Health Econ. 2007;8(3):279-85.

31. Blendon RJ, Kim M, Benson JM. The public versus the World Health Organization on health system performance. Health Aff (Millwood). 2001;20:101.

32. Bowers MR, Swan JE, Koehler WF. What Attributes Determine Quality and Satisfaction with Health-Care-Delivery. Health Care Manage Rev. 1994 FAL;19(4):49-55.

33. Calnan MW, Sanford E. Public trust in health care: the system or the doctor? Qual Saf Health Care. 2004;13(2):92-7.

34. Schoen C, Blendon RJ, DesRoches CM, Osborn R. Comparison of health care system views and experiences in five nations, 2001. Issue Brief N Y Commonw Fund. 2002;(542):1-6.

35. Mau S. Patterns of popular support for the welfare state. Berlin: WZB, Abt. Sozialstruktur und Sozialberichterstattung; 2001.

36. Svallfors S. The moral economy of class: class and attitudes in comparative perspective. Stanford, Calif.: Stanford University Press; 2006.

37. Svallfors S. The political sociology of the welfare state: institutions, social cleavages, and orientations. Stanford, Calif.: Stanford University Press; 2007.

38. Svallfors S, Taylor-Gooby $\mathrm{P}$. The end of the welfare state? responses to state retrenchment. London; New York: Routledge; 1999.

39. Pierson P. The new politics of the welfare state. Oxford, England; New York: Oxford University Press; 2001.

40. Wendt C, Mischke M, Pfeifer M, Kohl J. How do Europeans perceive their healthcare system patterns of satisfaction and preference for state involvement in the field of healthcare. EurSociolRevEuropean Sociol Rev. 2010;26(2):177-92.

41. Esping-Andersen G. The three worlds of welfare capitalism. Princeton, N.J.: Princeton University Press; 1990. 
42. Borisova LV. Health care systems as determinants of health outcomes in transition countries: Developing classification. Soc Theory Health. 2011;9(4):326-54.

43. Blekesaune M, Quadagno J. Public Attitudes toward Welfare State Policies: A Comparative Analysis of 24 Nations. Eurosocirevi Eur Sociol Rev. 2003;19(5):415-27.

44. Hicks AM. Social democracy and welfare capitalism: a century of income security politics. Ithaca, NY: Cornell University Press; 1999.

45. Hofstede GH. Culture's consequences : international differences in work-related values. Beverly Hills, Calif.: Sage Publications; 1980.

46. Hofstede GH. Culture's consequences : comparing values, behaviors, institutions, and organizations across nations. Thousand Oaks, Calif.: Sage Publications; 2001.

47. ESS. European Social Survey (ESS). 2016. http://www.europeansocialsurvey.org/

48. Eikemo TA, Bambra C, Huijts T, Fitzgerald R. The First Pan-European Sociological Health Inequalities Survey of the General Population: The European Social Survey Rotating Module on the Social Determinants of Health. Eur Sociol Rev Eur Sociol Rev. 2016.

49. StataCorp. Stata Statistical Software: Release 14. College Station, TX: StataCorp LP; 2015.

50. Triandis HC. Individualism \& collectivism. Boulder: Westview Press; 1995.

51. World Bank. Health Indicators. 2016. [accessed 2016 May 08]. Available from: http://data.worldbank.org/topic/health

52. World Health Organization. Global Health Expenditure database. 2016 [accessed 2016 May 10]. Available from: http://www.who.int/hrh/statistics/hwfstats/en/

53. World Health Organization. Global Health Workforce statistics. 2016 [accessed 2016 May 10]. Available from: http:/www.who.int/hrh/statistics/hwfstats/en/

54. Schwarz G. Estimating the Dimension of a Model. Ann Stat. 1978;6(2):461-4. 
55. Snijders TAB, Bosker RJ. Modeled Variance in Two-Level Models. Sociol Methods Res. 1994;22(3):342-63.

56. Baskerville RF. Hofstede never studied culture. Account Organ Soc. 2003 Jan;28(1):1-14. 


\section{Tables}

Table 1. Descriptive statistics for country level variables

\begin{tabular}{l|llllllllll} 
Country & PDI & IDV & MAS & UAI & Phys. & THE & OOP & $\begin{array}{c}\text { HC } \\
\text { mean }\end{array}$ & $\begin{array}{c}\text { HC } \\
\text { SD }\end{array}$ & N \\
\hline AT & 11 & 55 & 79 & 70 & 4.8 & 11.1 & 16.2 & 6.61 & 2.18 & 1765 \\
BE & 65 & 75 & 54 & 94 & 4.9 & 10.6 & 17.9 & 7.48 & 1.46 & 1747 \\
CH & 34 & 68 & 70 & 58 & 4.0 & 11.7 & 25.8 & 7.31 & 1.84 & 1498 \\
CZ & 57 & 58 & 57 & 74 & 3.6 & 7.5 & 14.5 & 6.09 & 2.25 & 2010 \\
DE & 35 & 67 & 66 & 65 & 3.9 & 11.2 & 13.2 & 5.86 & 2.25 & 2983 \\
DK & 18 & 74 & 16 & 23 & 3.5 & 11.2 & 12.9 & 6.58 & 2.08 & 1472 \\
EE & 40 & 60 & 30 & 60 & 3.2 & 6.5 & 20.3 & 4.82 & 2.27 & 2007 \\
ES & 57 & 51 & 42 & 86 & 4.9 & 9.1 & 23.5 & 5.28 & 2.54 & 1887 \\
FI & 33 & 63 & 26 & 59 & 2.9 & 9.5 & 18.2 & 6.84 & 1.96 & 2067 \\
FR & 68 & 71 & 43 & 86 & 3.2 & 11.6 & 6.3 & 6.31 & 2.09 & 1894 \\
GB & 35 & 89 & 66 & 35 & 2.8 & 9.3 & 9.5 & 6.01 & 2.32 & 2154 \\
HU & 46 & 80 & 88 & 82 & 3.1 & 7.5 & 27.3 & 3.35 & 2.40 & 1635 \\
IE & 28 & 70 & 68 & 35 & 2.7 & 8.0 & 17.4 & 4.09 & 2.44 & 2251 \\
IL & 13 & 54 & 47 & 81 & 3.3 & 7.9 & 26.5 & 6.23 & 2.24 & 2416 \\
LT & 42 & 60 & 19 & 65 & 4.1 & 6.6 & 30.9 & 4.98 & 2.21 & 2138 \\
NL & 38 & 80 & 14 & 53 & 2.9 & 11.0 & 5.2 & 5.96 & 2.03 & 1869 \\
NO & 31 & 69 & 8 & 50 & 4.3 & 9.4 & 13.9 & 6.83 & 1.95 & 1422 \\
PL & 68 & 60 & 64 & 93 & 2.2 & 6.4 & 23.5 & 3.51 & 2.38 & 1568 \\
PT & 63 & 27 & 31 & 104 & 4.1 & 9.6 & 26.4 & 4.62 & 2.55 & 1239 \\
SE & 31 & 71 & 5 & 29 & 3.9 & 12.0 & 14.1 & 5.77 & 2.10 & 1719 \\
SI & 71 & 27 & 19 & 88 & 2.5 & 9.3 & 12.1 & 4.59 & 2.37 & 1183 \\
\end{tabular}

Abbreviations:

Hofstede Cultural dimensions: power distance (PDI), individualism (IDV), masculinity (MAS), and uncertainty avoidance (UAI);

Phys. - physician density (per 1000 people)

THE - total health care expenditure (\% of GDP)

OOP - out-of-pocket health expenditure (\% of THE)

HC mean, HC SD - mean score and standard deviation of the dependent variable (HC evaluation)

$\mathrm{N}$ - number of observations

Countries: Austria (AT), Belgium (BE), Czech Republic (CZ), Denmark (DK), Estonia (EE), Finland (FI), France (FR), Germany (DE), Great Britain (GB), Hungary (HU), Ireland (IE), Israel (IL), Lithuania (LT), Netherlands (NL), Norway (NO), Poland (PL), Portugal (PT), Slovenia (SI), Spain (ES), Sweden (SE), Switzerland (CH) 
Table 2. Descriptive statistics for all individual level variables

\begin{tabular}{|c|c|c|}
\hline Variable & $\begin{array}{l}\text { Proportion of the } \\
\text { sample (\%) }\end{array}$ & $\begin{array}{l}\text { Mean satisfaction with health care } \\
\text { within each group }\end{array}$ \\
\hline \multicolumn{3}{|r|}{ a } \\
\hline 24 and under & 11.2 & 6.29 \\
\hline $25-34$ & 14.0 & 5.72 \\
\hline $35-44$ & 16.1 & 5.54 \\
\hline $45-54$ & 17.1 & 5.52 \\
\hline $55-64$ & 17.2 & 5.45 \\
\hline $65-74$ & 14.7 & 5.69 \\
\hline 75 and above & 9.8 & 5.96 \\
\hline \multicolumn{3}{|l|}{ Gender } \\
\hline Male & 46.9 & 5.89 \\
\hline Female & 53.1 & 5.52 \\
\hline \multicolumn{3}{|l|}{ Education } \\
\hline Low (primary) & 26.9 & 5.58 \\
\hline Medium (secondary) & 50.2 & 5.64 \\
\hline High (tertiary) & 22.9 & 5.94 \\
\hline \multicolumn{3}{|l|}{ Financial strain } \\
\hline $\begin{array}{l}\text { Difficult or very } \\
\text { difficult }\end{array}$ & 21.5 & 4.99 \\
\hline Comfortably or coping & 78.5 & 5.89 \\
\hline \multicolumn{3}{|l|}{ Self-reported health } \\
\hline Very good, good, or fair & 92.3 & 5.76 \\
\hline Bad or very bad & 7.7 & 4.89 \\
\hline \multicolumn{3}{|l|}{ Unmet need } \\
\hline Yes & 12.2 & 4.91 \\
\hline No & 87.8 & 5.80 \\
\hline
\end{tabular}


Table 3. Stepwise multilevel regression analysis. Dependent variable: public evaluation of national health care

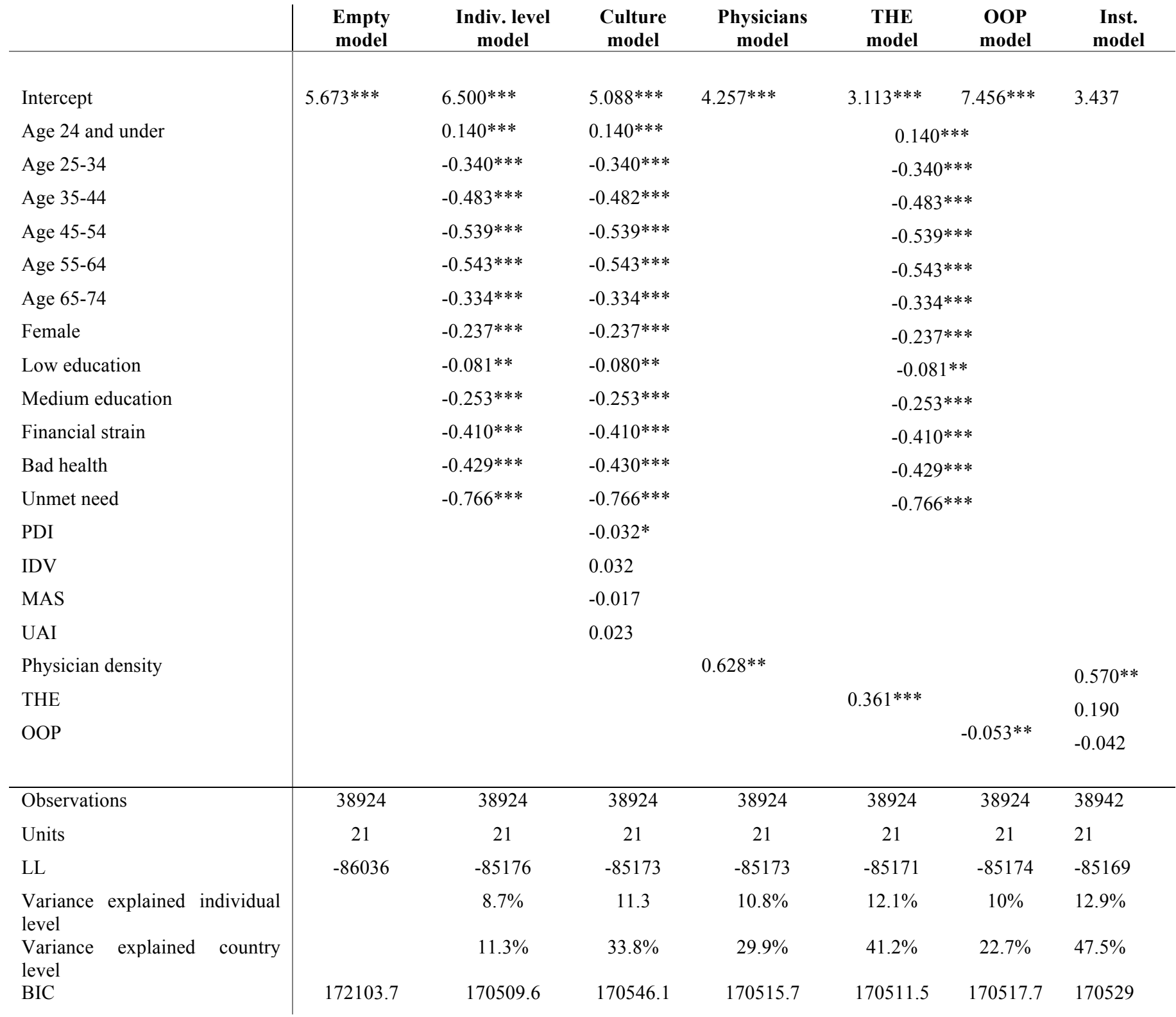

Note: $*=0.1$ significance level, $* *=0.05$ significance level, $* * *=0.01$ significance level; only coefficients are reported, other statistics available on request. 